International Journal of Medical Sciences

ISSN 1449-1907 www.medsci.org 2008 5(3):152-158

Research Paper

(C) Ivyspring International Publisher. All rights reserved

\title{
Of rodents and humans: a light microscopic and ultrastructural study on cardiomyocytes in pulmonary veins
}

\author{
Josef Mueller-Hoecker1', Frigga Beitinger ${ }^{1}$, Borja Fernandez², Olaf Bahlmann¹, Gerald Assmann¹, Christian \\ Troidl $^{3}$, Ilias Dimomeletis ${ }^{4}$, Stefan Kääb4, Elisabeth Deindl5
}

1. Institute of Pathology, Ludwig-Maximillians-University Munich, Germany

2. Faculty of Science, University of Malaga, Spain

3. Kerckhoff Klinik Bad Nauheim, Germany

4. Klinikum Grosshadern, Ludwig-Maximillians-University Munich, Germany

5. Walter-Brendel-Centre of Exp. Medicine, Ludwig-Maximillians-University Munich, Germany

Correspondence to: Elisabeth Deindl, PhD, Walter-Brendel-Centre of Exp. Medicine, Ludwig-Maximillians-University Munich, Marchioninistr. 27, D-81377 München, Germany. e-mail: elisabeth.deindl@med.uni-muenchen.de; Phone: ++49 / 89 / 2180-76504; Fax: ++49 / 89 / 2180-76503

Received: 2008.03.17; Accepted: 2008.06.22; Published: 2008.06.24

Cardiomyocytes in pulmonary veins (PVs) have been reported in rodents and humans. In humans they were related to atrial arrhythmias, including atrial fibrillation (AF). To investigate histological similarities and differences in PV cardiomyocyte localization and distribution, we performed comparative light and electron microscopic studies on humans, rats and mice, and generated a transgenic mouse strain. Results on mice $(\mathrm{C} 57 \mathrm{BL} / 6$ and $\mathrm{BALBc})$ and rats (Wistar) revealed that cardiomyocytes regularly extend from the hilus along venous vessels into the lung tissue surrounding individual intrapulmonary veins of varying diameters $(70-250 \mu \mathrm{m})$. The cardiomyocytes showed the ultrastructure of a normal working myocardium with intact intercalated discs and tightly packed contractile filaments. In both lung and hilus cardiomyocytes were localized either close to the basal lamina of the endothelium or separated from it by smooth muscle cells and/or collagen fibres. In humans (autopsies, $n=20$ ) extrapericardiac cardiomyocytes were only found in 23 out of 78 veins and showed an incomplete sleeve at the lung hilus. In addition, cardiomyocytes occurred significantly more often in right than in left veins, however, never in intrapulmonary veins.

We discuss the hypothesis that the variance in distribution of PV cardiomyocytes in humans and rodents might reflect the difference in pathogenesis and development of AF.

Key words: cardiomyocytes, pulmonary veins, electron microscopy, atrial fibrillation

\section{Introduction}

Animal and human histological studies on pulmonary veins (PVs), which date back to the $19^{\text {th }}$ century, reported the presence of cardiac cells beyond the atrio-venous junctions [1-5]. The observations of independent pulsations of PVs have raised the possibility that PVs contain pacemaker cells [6]. Morphological studies on rats suggested the presence of conducting cells in PVs [7,8] and Perez-Lugones et al. found pace-maker cells, transitional cells and Purkinje cells in human PVs [9]. Spontaneous electrical activity with phase 4 depolarization was for the first time demonstrated in guinea pigs [10]. Moreover, it was shown that digitalis could trigger atrial tachyarrhythmias in PV tissue preparations [11]. Studies on patients with drug-refractory paroxysmal atrial fibrillation identified potential triggers of $\mathrm{AF}$ from electrically active cardiomyocytes localized in the ostia of pulmonary veins [12]. Atrial fibrillation is the most common cardiac arrhythmia in humans, however, not of major concern in small rodents. Nevertheless, ontological and functional investigations on pulmonary myocardium have been extensively performed in mice and rats (e.g. [13,14]). This fact prompted us to perform a comparative histological and ultrastructural study on the occurrence of cardiomyocytes along PVs in humans, mice and rats. We focussed on the distribution of cardiomyocytes in PVs as well as their topographical relation to the vessel wall.

\section{Materials und Methods}

\section{Animal care}

Animal care and all experimental procedures were performed in strict accordance to the German and National Institutes of Health animal legislation guidelines and were approved by the local animal care committees. 


\section{Histological studies}

Lungs of 19 mice (C57BL/ 6 and BALBc) and 3 rats (Wistar) were excised and fixed in $4 \%$ buffered formalin, dehydrated in graded ethanol and embedded in paraffin by standard methods. Four $\mu \mathrm{m}$ thick longitudinal sections of the hilus were mounted on positively charged glass slides. Subsequently, the sections were stained with hematoxilin/eosin, elastic van Gieson and Masson`s trichrome according to standard procedures. For measurements of the vessel size a Periplan ocular GF12,5x/20 with integrated scale (Leitz) was used.

Additionally, lung veins from 20 randomly chosen human autopsy cases (14 males, 6 females; median age 68 years (range 46 - 83 years) were investigated. In every case circular cross-sections were taken at the lung hilus, and at the outer and inner surface of the pericardium. The tissue samples were processed and stained as described above. In total 78 human lung veins were studied (Table 1).

Table 1. Cardiomyocytes in human lung veins (autopsy cases $n$ $=20)$.

\begin{tabular}{|c|c|c|c|c|c|}
\hline & & & $\begin{array}{l}\text { inside the } \\
\text { pericardium }\end{array}$ & $\begin{array}{l}\text { outside the } \\
\text { pericardium }\end{array}$ & p-value \\
\hline \multirow[t]{6}{*}{ A } & \multirow[t]{3}{*}{ right veins } & upper vein & 19 / 20 & $9 / 19$ & $0,001^{*}$ \\
\hline & & lower vein & $16 / 19$ & $7 / 19$ & $0,007^{*}$ \\
\hline & & both veins & 35 / 39 & $16 / 38$ & $<0,001^{*}$ \\
\hline & \multirow[t]{3}{*}{ left veins } & upper vein & $16 / 20$ & $4 / 20$ & $<0,001^{*}$ \\
\hline & & lower vein & 15 / 19 & $3 / 19$ & $<0,001^{*}$ \\
\hline & & both veins & $31 / 39$ & $7 / 39$ & $<0,001^{*}$ \\
\hline & & & right veins & left veins & p-value \\
\hline \multirow[t]{9}{*}{ B } & \multirow{3}{*}{$\begin{array}{l}\text { inside the } \\
\text { pericardium }\end{array}$} & upper vein & 19 / 20 & 16 / 20 & \multirow[t]{3}{*}{0,347} \\
\hline & & lower vein & $16 / 19$ & $15 / 19$ & \\
\hline & & both veins & 35 / 39 & $31 / 39$ & \\
\hline & \multirow{3}{*}{$\begin{array}{l}\text { outside the } \\
\text { pericardium }\end{array}$} & upper vein & $9 / 19$ & $4 / 20$ & \multirow[t]{3}{*}{$0,026^{*}$} \\
\hline & & lower vein & $7 / 19$ & $3 / 19$ & \\
\hline & & both veins & $16 / 38$ & $7 / 39$ & \\
\hline & \multirow[t]{3}{*}{ hilus } & upper vein & $4 / 20$ & $1 / 20$ & \multirow[t]{3}{*}{0,087} \\
\hline & & lower vein & $4 / 19$ & $1 / 19$ & \\
\hline & & both veins & $8 / 39$ & $2 / 39$ & \\
\hline
\end{tabular}

A, Comparison inside/outside the pericardium of left and right veins with cardiomyocytes.

B, Comparison left/right veins with cardiomyocytes inside and outside the pericardium.

Statistical significance $\left({ }^{*}\right)$ was accepted at $\mathrm{p} \leq 0.05$.

\section{Ultrastructural studies}

For ultrastructural studies lung tissue including the hilus region of mice and rats were fixed in $6.25 \%$ phosphate buffered glutaraldehyde, postfixed in osmium tetroxide ( $1 \%$ in distilled water, 2 hours), dehydrated in ethanol and embedded in Epon. Semithin sections were stained with azure-methylene-blue. Ultrathin sections were counterstained with uranyl acetate and lead citrate and examined with a Philips EM 420 transmission electron microscope.

\section{Transgenic mice ( $\alpha$ MHCp-LacZ-hgh)}

The presence and localization of cardiomyocytes in murine pulmonary veins was investigated by means of $\beta$-galactosidase analyses in transgenic mice ( $\alpha$ MHCp-lacZ-hgh) with cardiomyocyte-specific expression of the LacZ reporter gene.

Cloning strategy of $\alpha M H C p-L a c Z-h g h$. The vector $\alpha M H C p-M C S-h g h$ was a kind gift from Dr. J. Robbins (Cincinnati, USA). This Vector (pBS II sk+) contained the $5537 \mathrm{bp}$ promoter fragment upstream of the $\alpha \mathrm{MHC}$ gene from mouse and the first 3 noncoding exons/introns of the $\alpha \mathrm{MHC}$ gene. The multiple cloning side was followed by the sequence of the human growth hormone poly(A) signal (hgh). The LacZ coding sequence was PCR-amplified from pcDNA4/TO/lacZ (Invitrogen) using two pairs of sequence specific primers. After cloning the fragments into Blunt II TOPO (Invitrogen) they were again isolated using Sal I/BssH II and BssH II/HindIII. After ligation using the BssH II restriction site the complete LacZ cDNA was integrated into $\alpha$ MHCp-MCS-hgh using the restriction enzymes Sal I and Hind III.

Establishing $\alpha M H C p-L a c Z-h g h$ transgenic mouse lines. The transgene ( $\alpha \mathrm{MHCp}$-LacZ-hgh) was isolated from the vector using a Not I restriction enzyme, and gel-purified using QIAquick Gel Extraction Kit (Qiagen). $\alpha \mathrm{MHCp}$-LacZ-hgh transgenic mice were established by microinjection of 1-3 $\mu \mathrm{g}$ transgene into the pronuclei of fertilized FVB/N oocytes [15]. After crossing with vasectomised males the oocytes were retransferred into the oviduct of pseudo pregnant females. The transgenic mouse lines were established and propagated in FVB-inbred-strains.

$\beta$-galactosidase (X-Gal) staining. Animals were killed by an anesthetic overdose. The hearts were exposed, cannulated through the left ventricle, and tissue was perfused with $15 \mathrm{ml}$ of phosphate buffer $(\mathrm{pH}=7.4)$ (PBS). Then the lungs were fixed with $50 \mathrm{ml}$ of 3\% paraformaldehyde in PBS, and finally washed with PBS for $3 \mathrm{~min}$. After dissection, the lungs were rinsed 3 times with PBS for 5 minutes each.

For whole mount staining, the lungs were incubated in 0,1\% X-gal, $5 \mathrm{mM}$ potassium ferricyanide, $5 \mathrm{mM}$ potassium ferrocyanide, $1 \mathrm{mM}$ magnesium chloride, 0,002\% NP-40, 0,01\% sodium deoxycholate, PBS, $\mathrm{pH}=7,0$, at $37^{\circ} \mathrm{C}$ for 3 hours to overnight. The lungs were rinsed in $\mathrm{PBS}$, and postfixed at $4^{\circ} \mathrm{C}$ overnight in $2 \%$ paraformaldehyde, $0,1 \%$ glutaraldehyde, PBS. Postfixed lungs were rinsed in 
PBS, dissected again in some cases, and photographed under a binocular microscope (Carl Zeiss OPMI-FR).

For histological analyses, the dissected lungs were equilibated in a graded series of sucrose, and mounted in OCT (Tissue-Tek) using liquid nitrogen-cooled isopentane. Ten to $20 \mu \mathrm{m}$ thick cryosections were mounted on slides, postfixed in $2 \%$ paraformaldehyde in PBS, rinsed in PBS, and stained using the same solutions as described above. The sections were then rinsed in PBS, postfixed in $2 \%$ paraformaldehyde, 0,1\% glutaraldehyde, PBS, rinsed again and photographed under a optical microscope (Leica DM RB).

\section{Statistics}

For statistical analyses of the autopsy results the Fisher' exact test was applied. Statistical significance was accepted at $\mathrm{p} \leq 0.05$.

\section{Results}

\section{Lung veins in mice and rats}

Both in mice and rats a coat of cardiomyocytes was found within pulmonary veins of lungs (Fig. 1A, B) and at the lung hilus (Fig. 1C, D). Within the lungs the cardiomyocytic coat was present in veins measuring 70-250 $\mu \mathrm{m}$, but not in every vessel of the same size (Fig. 1A). The cardiomyocyte coat varied between 4-8 cell layers at the hilus and 1 to 2 layers at intrapulmonal locations. However, cardiomyocyte coverage was highly variable not only among specimens, but among veins of the same specimen. Furthermore, in some areas the cardiomyocytic coat was partially incomplete or discontinuous, in particular within lungs (Fig. 1A, B). This fact was conspicuously evidenced in pulmonary veins of transgenic mice by $\alpha \mathrm{MHC}$-specific lacZ staining (Fig. 2). Ultrastructural studies disclosed that both within the lungs and at the lung hilus cardiomyocytes were located either adjacent to the basal lamina (Fig. 3A, D) or separated by smooth muscle cells, collagen and elastic fibres (Fig. 3B, C). The cardiomyocytes showed the normal fine structure of a working myocardium, i.e. rich in contractile filaments, mitochondria, and lamellar cristae. The cells formed regular cell to cell contacts at intercalated discs (Fig. 3A, B) and were separated from the surrounding lung by collagen fibres and fibrocytes (Fig. 3 E).

\section{Lung veins in humans}

In humans, cardiomyocytes covered the lung veins up to the inner surface of the pericardium in $84 \%$ $(66 / 78)$ of the veins examined, but were present near the outer surface of the pericardium only in $29 \%$ $(23 / 78)$ of them (Table $1 \mathrm{~A})$. Sixteen of the 23 veins with cardiomyocytes near the outer surface of the pericardium were right lung veins and only 7 were left lung veins $(p=0.026)$ (Table $1 B)$. At the hilus, cardiomyocytes were found only in $13 \%$ (10/78) of lung veins belonging to 5 different autopsy cases $(p<0.0001)$. In cross sections the sleeve of cardiomyocytes covered between $10 \%$ and $100 \%$ of the total circumference of a vein. The maximum coverage was found near the auricular ostia. Histologically, the cardiomyocytes showed the typical compact cytoplasm of regular cardiomyocytes of the working myocardium (Fig. 4A, B).

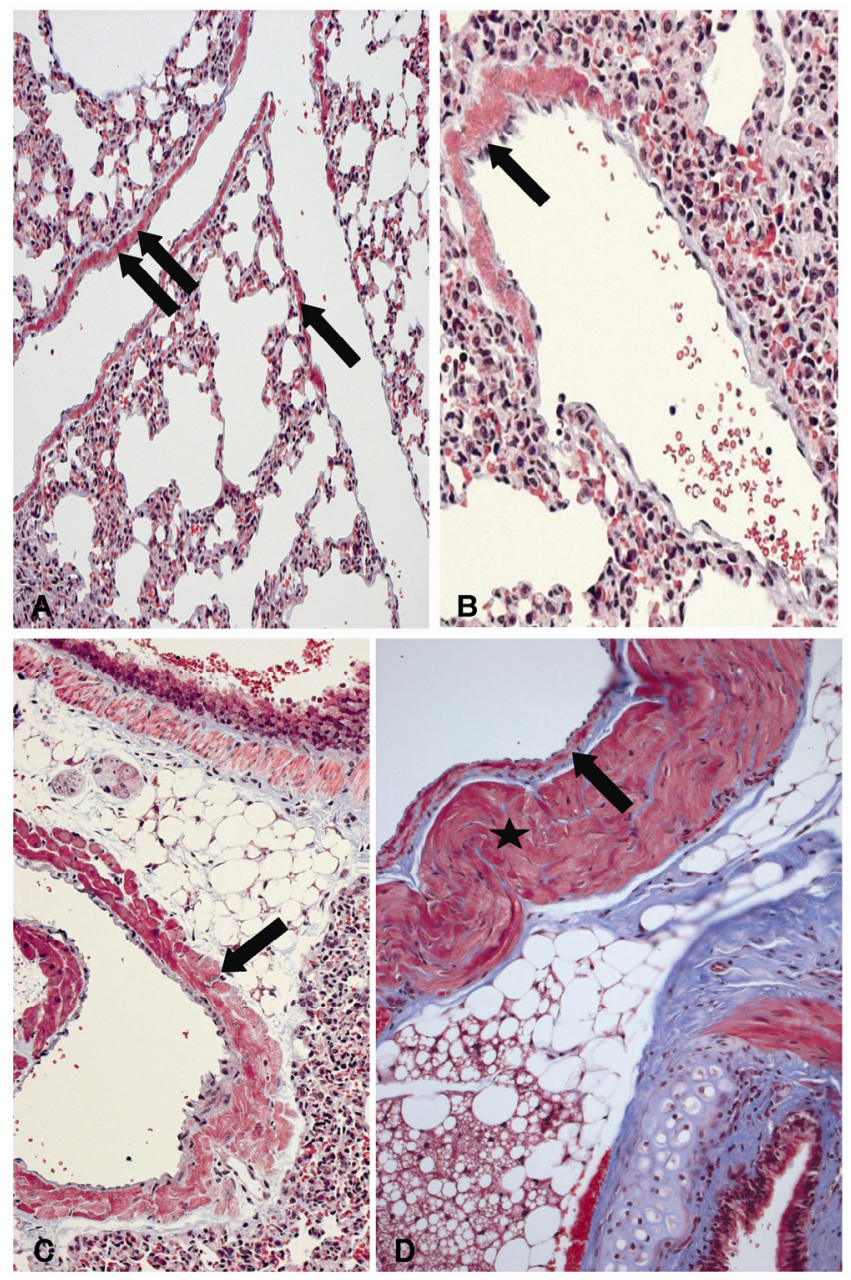

Fig. 1: Light microscopy of intrapulmonary veins of mice (A, B), and extrapulmonary veins of mice (C) and rats (D) at the lung hilus. A, The left intrapulmonary vein shows a continuous outer cell layer of cardiomyocytes (double arrow). The right vein of the same size has only a few discontinous cardiomyocytes (arrow). B, Intrapulmonary vein with a segmental coat of cardiomyocytes. Layers of cardiomyocytes are seen in the outer part of extrapulmonary veins of mice $(\mathbf{C}$, arrow) and rats (D, asterisk). In $\mathbf{D}$ (arrow), but not in $\mathbf{C}$, an inner rim of smooth muscle cells is present. Obj. magnification: A, 10x; B, 16x; C, 25x; D, 40x. 


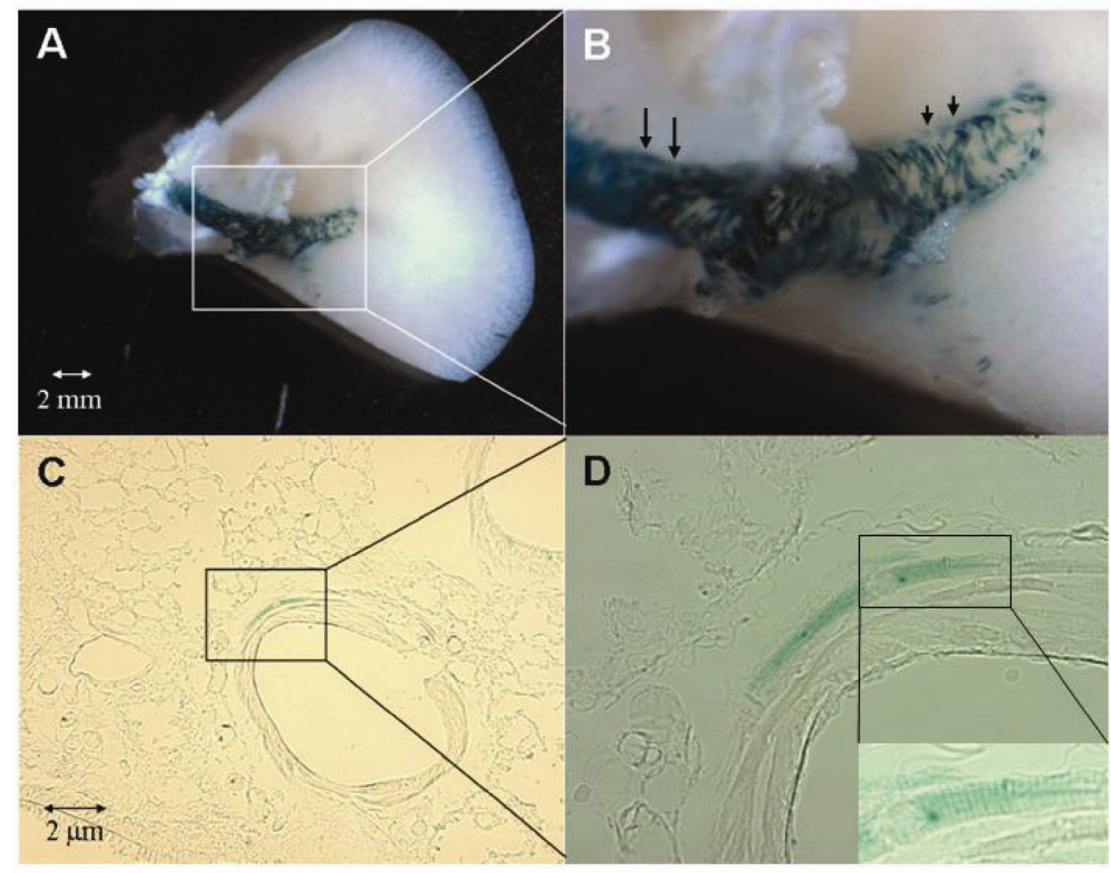

Fig. 2: Whole mount $(A, B)$ and tissue section (C,D) $\beta$-gal staining of PVs of $\alpha M H C p$-LacZ-hgh transgenic mice. Blue $\beta$-gal staining is evident only in cardiomyocytes covering the PVs. Note that the cardiomyocytic coverage is more prominent in the proximal (long arrows in B) than in the distal (short arrows in B) portions of the extrapulmonary veins. At intrapulmonary locations $(\mathbf{C}, \mathbf{D})$, the cardiomyocytic coverage is even more reduced. Note the striated appearance of $\beta$-gal-positive cells (inset in D). Original magnification: C, 200x; D, 400x; inset in D, 630x

Fig. 3: Ultrastructure of intrapulmonary veins of mouse $(A, C)$ and rat $(B)$ and extrapulmonary vein of rat (D) at the lung hilus and relation of intrapulmonary lung vein (mouse) to lung parenchyma (E). A, Intrapulmonary vein (mouse). Directly underneath the basal/ elastic lamina $(* *)$ cardiomyocytes of the working myocardium type are seen. B, Intrapulmonary vein of rat showing a smooth muscle cell (sm) interposed between endothelium and the cardiomyocytic layer. C, Intrapulmonary vein of mouse, with a smooth muscle cell layer $(\mathrm{sm})$ and elastic fibres $(* * *)$ separating the cardiomyocytes from the endothelium. D, Extrapulmonary vein (rat) at the lung hilus. The cardiomyocyte layer is directly underneath the basal lamina. E, Relation of intrapulmonary lung vein (mouse) to lung parenchyma. The vein is devoid of a smooth muscle cell coat. The cell layer of cardiomyocytes (C) is separated from the lung parenchyma (LP) by collagen fibres (double arrow) and fibrocyte $(+) . \mathrm{L}=$ lumen, $\mathrm{N}=$ nucleus of cardiomyocyte, $\mathrm{E}=$ erythrocyte; $\mathrm{C}=$ cardiomyocyte, $\mathrm{LP}=$ lung parenchyma, $\mathrm{sm}=$ smooth muscle cells, $\mathrm{cf}$ $=$ contractile filaments, $\mathrm{m}=$ mitochondra, $+=$ fibrocyte, $*=$ endothelium, $* *=$ basal/elastic lamina, $* * *$ = elastic material; arrow $=$ intercalated disc, double arrow $=$ collagen fibers, arrow head $=$ endothelium with adjacent basal/elastic lamina. Original magnification: A, D: $10.000 x ; \mathrm{B}, \mathrm{C}$ : 20.000x; E, 2000x
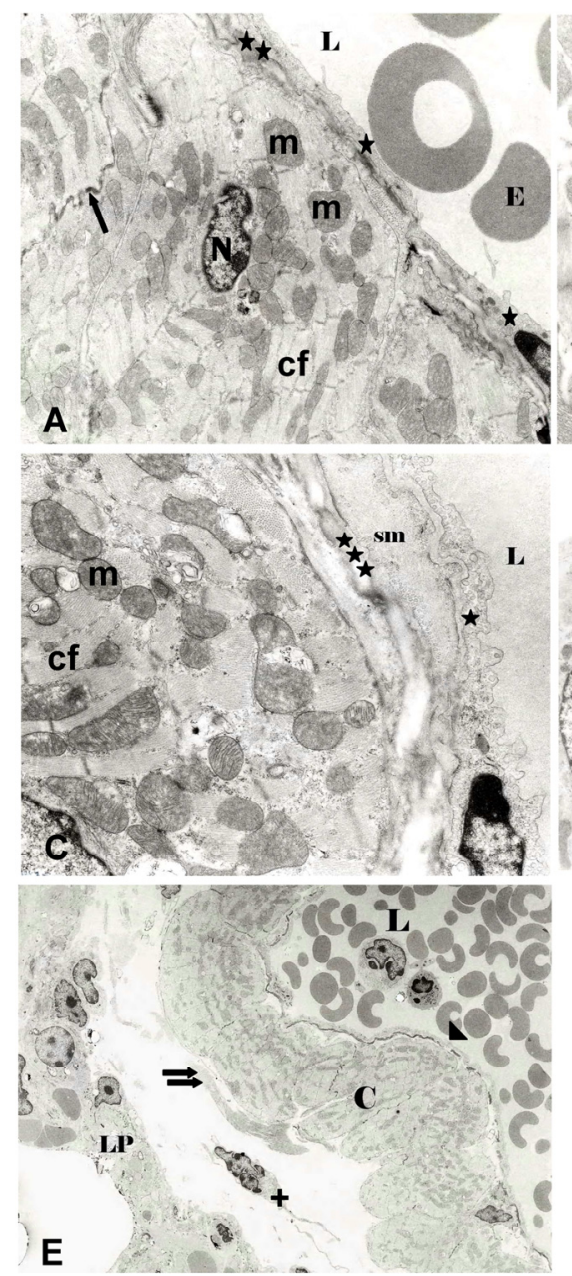
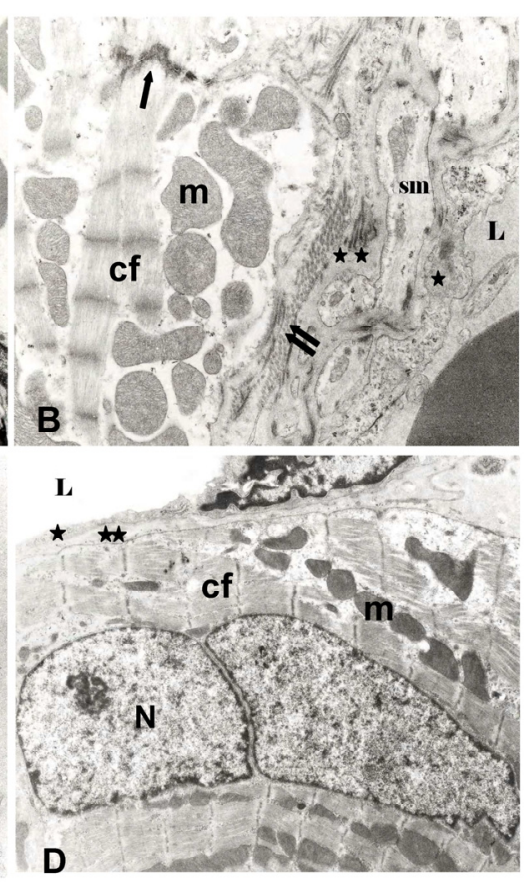


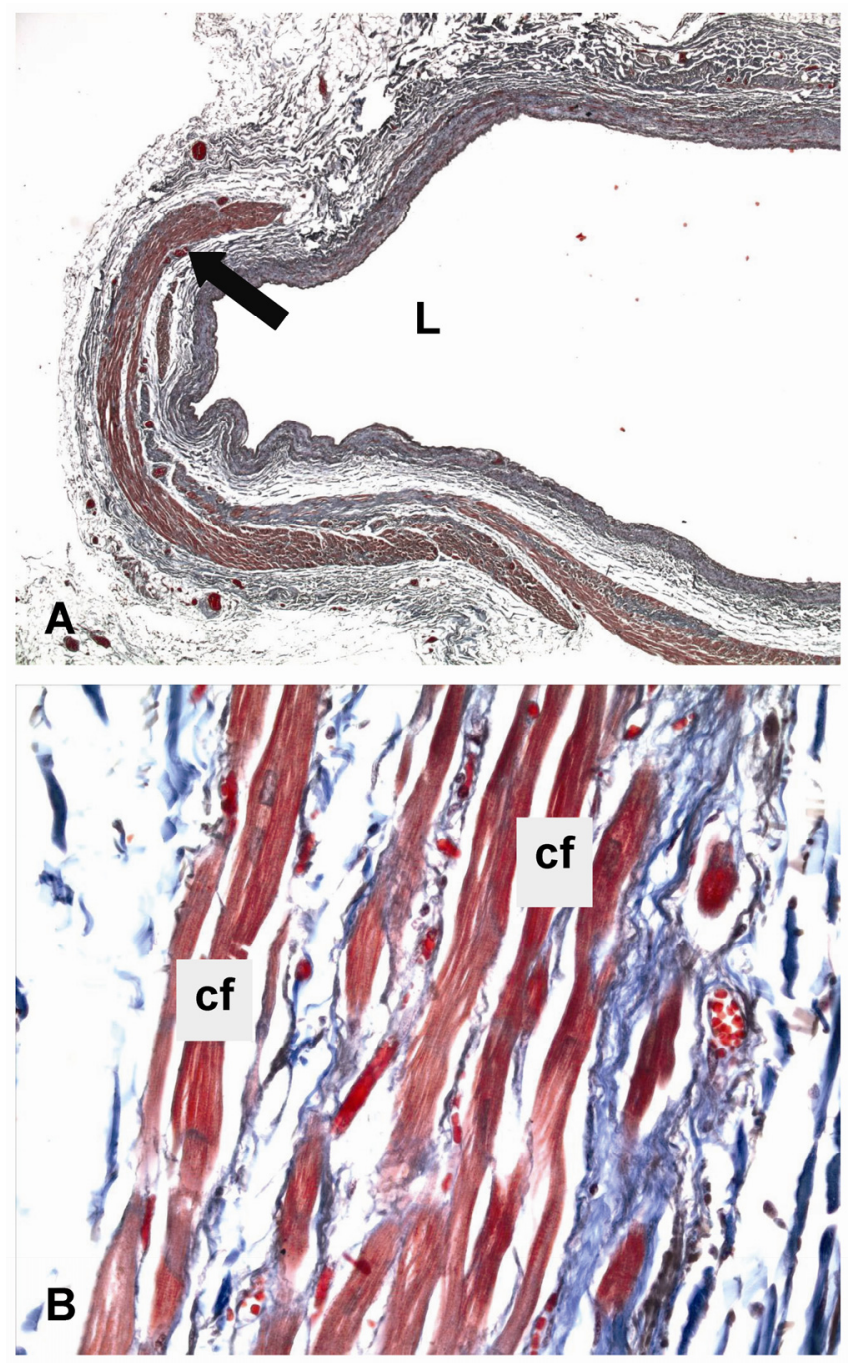

Fig. 4: Light microscopy of human lung veins. Masson's trichrome staining of human lung veins at the lung hilus with an incomplete sleeve of cardiomyocytes (arrow). $\mathrm{L}=$ lumen, $\mathrm{cf}=$ contractile filament. Original magnification: A, 25x; B, 400x

\section{Discussion}

Our histological and ultrastructural study on the occurrence of cardiomyocytes in PVs of humans as well as of mice and rats showed major differences in cardiomyocyte distribution and localization. These data might be of considerable relevance in terms of understanding the development of AF in humans as well as on the choice of animal models of $\mathrm{AF}$ as discussed below.

In our study on mice and rats we found cardiomyocytes forming part of PV walls in all lungs under investigation. In mice, their occurrence and distribution was not related to a specific strain, being similar both in C57BL/6 mice and in BALBc-mice. Cardiomyocytes were found in vessels with diameters varying from $70-250 \mu \mathrm{m}$. However, their occurrence had a random character, not being present in every vessel of the same size. At the hilus the presence of cardiomyocytes was a constant feature, whereas in vessels less than $70 \mu \mathrm{m}$ no cardiomyocytes were found. These data were in accordance with the lac $Z$ expression in transgenic $\alpha \mathrm{MHCp}$-lacZ mice that were generated to get a more overall impression of cardiomyocyte distribution in mice.

In mice and rats, the structural relationship of cardiomyocytes within the vessel wall was also variable. Cardiomyocytes could be found either in close contact with the basal lamina of the endothelium without intervening smooth muscle cells or in a more outward position adjacent to smooth muscle cells, collagen and elastic fibres. Detailed ultrastructural data on the topographical variability of PV cardiomyocytes are only rarely available in the literature [7,8,16-18]. The observed structural variability observed in our study, however, may explain the discrepancy of the results of some studies on the existence of a layer of smooth muscle cells between the endothelial lining and the external cardiomyocyte sleeve. The intimate location near the endothelium at least of the intrapulmonal cardiomyocytes often without interposed smooth muscle cells further indicates that they represent an integral part of the venous wall as previously suggested [8].

In humans, cardiomyocytes did not occur in intrapulmonary veins. Furthermore, $87 \%$ of the lung veins at the lung hili were free of them. In the literature, the percentage of individuals with cardiomyocytes at any level of the extrapulmonary veins ranged from $68 \%$ to $97 \%$ [19-21]. In our series, $84 \%$ of autopsy cases showed cardiomyocyte coverage of pulmonary veins, a percentage similar to that reported by other authors [5]. However, this coverage was not continuous in all locations. Maximal coverage was found near the auricular ostium, whereas incomplete layers appeared near the pericardium. Moreover, only in $30 \%$ of the autopsy cases examined, cardiomyocytes surpassed the pericardial limit indicating that the pericardium represents a natural boarder. Previous studies indicated that in humans the cardiomyocytic perivenous extension varied between $25-48 \mathrm{~mm}$ at maximum $[1,19,20,22]$ and $1.8-3 \mathrm{~mm}$ at minimum $[1,20]$, but no direct reference to the pericardial limit was made. In our study, we found that extrapericardiac cardiomyocytes occurred significantly more often in right veins than in left veins. Large interindividual variabitility, however, is a well known feature $[19,20]$. In PVs of patients with atrial fibrillation P cells, transitional cells, and Purkinje 
cells have been documented [9]. Node-like cells have been found in PVs of rat hearts [7]. However, our present results indicate that PV cardiomyocytes belong exclusively to the working myocardium both in humans and rodents. Furthermore, according to the expression of the conducting gap-junction protein Cx40 and the missing expression of Hcn4 in mice, a pacemaker channel essential for pacemaker acivity in humans [23,24], the existence of a nodal-like phenotype is unlikely in PV cardiomyoytes of mice [14].

In our study, we found that the distribution of cardiomyocytes in mice and rats is similar, confirming previous results $[7,16,18]$. In both rodent species, pulmonary vein cardiomyocytes extend from the atrium through the hilus into the lungs. However, this distribution differs strongly from that of humans, in which pulmonary vein cardiomyocytes never reach the lungs indicating that in humans the pericardium presents a natural barrier for PV cardiomyocytes. It is of special interest to know that the anatomical location of intrapulmonary lung veins also differs in mice and rats from that in humans. In both rodents the pulmonary veins follow the pulmonary arteries and bronchus, whereas in humans the lung veins follow an independent course in fibrous interlobular septae. It is tempting to speculate that the observed differences in the pulmonary vein architecture may account for a different physiological function. According to a detected propagation of the action potential towards the lung murine PV cardiomyocytes might have a "throttle valve"-like action role [8]. By preventing backflow of blood into the lung during diastole they might protect the organ from edema formation. Due to lower heart beat rate a similar action is not necessary in humans.

Beside these anatomical differences, the basic histological and ultrastructural characteristics of PV cardiomyocytes are very similar in rodents and man. In both, working myocytes surround PVs in intimate association with the endothelium or separated from it by a layer of SMCs. Accordingly, and in contrast to old views of cardiac inflow tract development, it has been shown that the early events in the development of the pulmonary vein are likely to be the same in all mammals, including humans [25]. Experimental research on mouse embryogenesis indicates that cardiomyocitic coverage of the pulmonary veins develop as an outgrowth of atrial cells that migrate to the lung primordium to finally connect to the pulmonary vein vascular plexus[13,26,27]. However, others favoured the hypothesis that lung mesenchymal cells differentiate into myocardial cells in situ [28]. Recently, Mommersteeg et al. confirmed the later hypothesis and described a biphasic model for mice [14]. They proposed that first a mesenchymal-derived myocardial population forms de novo at the connection of the pulmonary vein and the atrium. In a second wave, this pulmonary myocardium population expands by proliferation, expansion and migration to form the pulmonary vein myocardial sleeve. In their study Mommersteeg et al. found that atrial and mesenchymal-derived cardiomyocytes chronologically differ in the expression of cardiac tropnin I (cTNI) during embryogenesis. A few years ago Millino et al. published a study on transgenic mice [13] showing that depending on TNI promoter length lacZ reporter gene was either expressed only in the atria or also in PVs, and hypothesized that cardiomyocytes of atria and PVs show differences in their transcriptional potential. However, in light of the more recent data of Mommersteeg it is likely, that the observed differences in transcription are due to the existence of two different myocardial cell populations in terms of origin in mice. Interestingly, these two cell populations differ in their sensitivity to genetic disturbance, being the PV cardiomyocytes more susceptible to a nodal-type phenotype shift [14]. Based on these observations, Mommersteeg and collaborators suggested that in humans, genetic variations between individuals might trigger PV cardiomyocyte phenotype shift, automaticity, and finally atrial fibrillation. Our results support this hypothesis. First, we found that human PV cardiomyocytes possess the working myocardium phenotype as predicted by the embryological studies of Mommersteeg. Second, the strong individual variability in human PV cardiomyocite coverage and distribution fits well with a model in which genetic variation accounts for a variable atrial fibrillation susceptibility.

Taking the results of the present study together with previous embryological research, and assuming that the physiological function of murine PV cardiomyocyte coverage has been lost in other mammals like humans, we propose that in man PV cardiomyocytes may represent a relict of PV embryogenesis, constituting a source of ectopic generation of independent re-entrant wavelets in a subset of patients with a genetic predisposition. This annotation might be a substantial working hypothesis for further experimental investigations in other mammals like guinea pigs in which cardiomyocytes only extend to the hilus [4] and spontaneous electrical activity has been observed.

\section{Acknowledgement}

The authors are indebted to Mrs Sabine Schaefer for valuable technical assistance and to Mrs Maria 
Wittmaier for careful help in the preparation of the manuscript. Furthermore, we want to thank Vincent Christoffels for helpful discussions.

\section{Conflict of interest}

The authors have declared that no conflict of interest exists.

\section{References}

1. Ho SY, Cabrera JA, Tran VH, Farre J, Anderson RH, Sanchez-Quintana D. Architecture of the pulmonary veins: Relevance to radiofrequency ablation. Heart 2001, 86:265-270.

2. Moubarak JB, Rozwadowski JV, Strzalka CT, Buck WR, Tan WS, Kish GF, Kisiel T, Fronc HC, Maloney JD. Pulmonary veins-left atrial junction: anatomic and histological study. Pacing Clin Electrophysiol 2000, 23:1836-1838.

3. Nathan H, Eliakim M. The junction between the left atrium and the pulmonary veins: an anatomic study of human hearts. Circulation 1966, 34:412-422.

4. Stieda L. Ueber quergestreifte Muskelfasern in der Wand von Lungenenvenen. Arch f Mikr Anat 1877, 14:243.

5. Tagawa M, Higuchi K, Chinushi M, Washizuka T, Ushiki T, Ishihara N, Aizawa Y. Myocardium extending from the left atrium onto the pulmonary veins: a comparison between subjects with and without atrial fibrillation. Pacing Clin Electrophysiol 2001, 24:1459-1463.

6. Brunton TL, Fayer L. Note on independent pulsation of the pulmonary veins and vena cava. Proc R Soc B 1876, 25:174-176.

7. Masani F. Node-like cells in the myocardial layer of the pulmonary vein of rats: an ultrastructural study. J Anat 1986, 145:133-142

8. Paes de Almeida O, Bohm CM, de Paula Carvalho M, Paes de Carvalho A. The cardiac muscle in the pulmonary vein of the rat: A morphological and electrophysiological study. J Morphol 1975, 145:409-434.

9. Perez-Lugones A, McMahon JT, Ratliff NB, Saliba WI, Schweikert RA, Marrouche NF, Saad EB, Navia JL, McCarthy PM, Tchou P, et al. Evidence of specialized conduction cells in human pulmonary veins of patients with atrial fibrillation. J Cardiovasc Electrophysiol 2003, 14:803-809.

10. Cheung DW. Pulmonary vein as an ectopic focus in digitalis-induced arrhythmia. Nature 1981, 294:582-584.

11. Cheung DW. Electrical activity of the pulmonary vein and its interaction with the right atrium in the guinea-pig. J Physiol 1981, 314:445-456.

12. Hoffmann E, Janko S, Reithmann C, Steinbeck G. Mechanisms of initiation in atrial fibrillation. Z Kardiol 2002, 91:24-32.

13. Millino C, Sarinella F, Tiveron C, Villa A, Sartore S, Ausoni S. Cardiac and smooth muscle cell contribution to the formation of the murine pulmonary veins. Dev Dyn 2000, 218:414-425.

14. Mommersteeg MT, Brown NA, Prall OW, de Gier-de Vries C, Harvey RP, Moorman AF, Christoffels VM. Pitx2c and Nkx2-5 Are Required for the Formation and Identity of the Pulmonary Myocardium. Circ Res 2007, 101:902-909.

15. Hogan B, Beddington R, Costantini F, Lacy E. Microinjecting DNA into pronuclei; in Manipulating the mouse embryo - a laboratory manual. New York: Cold Spring Harbor Laboratory Press; 1994.

16. Heppleston AG. The musculature of the aging mouse lung. A light and electron-microscope study. J Gerontology 1961, 16:106-109.

17. Karrer HE. The striated musculature of blood vessels. I. General cell morphology. J Biophys Biochem Cytol. 1959, 6:383-392.

18. Ludatscher RM. Fine structure of the muscular wall of rat pulmonary veins. J Anat 1968, 103:345-357.

19. Kholova I, Kautzner J. Anatomic characteristics of extensions of atrial myocardium into the pulmonary veins in subjects with and without atrial fibrillation. Pacing Clin Electrophysiol 2003, 26:1348-1355.

20. Rutger J, Hassink RJ, Aretz HT, Ruskin J, Keane D. Morphology of atrial myocardium in human pulmonary veins. A postmortem analysis in patients with and without atrial fibrillation. J Am Coll Cardiol 2003, 42:1108-1114

21. Saito T, Waki K, Becker AE. Left atrial myocardial extensions onto pulmonary veins in humans: Anatomic observations relevant for atrial arrhythmias. J Cardiovasc Electrophysiol 2000, 11:888-894.

22. Roux N, Havet E, Mertl P. The myocardial sleeves of the pulmonary veins: potential implications for atrial fibrillation. Surg Radiol Anat 2004, 26:285-289.

23. Milanesi R, Baruscotti M, Gnecchi-Ruscone T, DiFrancesco D. Familial sinus bradycardia associated with a mutation in the cardiac pacemaker channel. N Engl J Med 2006, 354:151-157.

24. Stieber J, Herrmann S, Feil S, Loster J, Feil R, Biel M, et al. The hyperpolarization-activated channel HCN4 is required for the generation of pacemaker action potentials in the embryonic heart. Proc Natl Acad Sci U S A 2003, 100:15235-15240.

25. Webb S, Brown NA, Wessel A, Anderson RH. Development of the murine pulmonary vein and its relationship to the embryonic venous sinus. Anat Rec 1998, 250:325-334.

26. Jones WK, Sanchez A, Robbins J. Murine pulmonary myocardium: developmental analysis of cardiac gene expression. Dev Dyn 1994, 200:117-128.

27. Lyons GE, Schiaffino S, Sassoon D, Barton P, Buckingham ME. Developmental regulation of myosin expression in mouse cardiac muscle. J Cell Biol 1990, 111:2427-2437.

28. van den Hoff MJ, Kruithof BP, Moorman AF. Making more heart muscle. Bioessays 2004, 26:248-261. 